\title{
AIDS and associated malignancies
}

\author{
Charles WOOD ${ }^{1, *}$, William HARRINGTON Jr${ }^{2}$ \\ ${ }^{1}$ Nebraska Center for Virology \& School of Biological Sciences, University of Nebraska, Lincoln, NE 68588, USA \\ ${ }^{2}$ Sylvester Cancer Center, University of Miami, Miami, FL 33136, USA
}

\begin{abstract}
AIDS associated malignancies (ARL) is a major complication associated with AIDS patients upon immunosuppression. Chronically immunocompromised patients have a markedly increased risk of developing lymphoproliferative disease. In the era of potent antiretrovirals therapy (ARV), the malignant complications due to HIV-1 infection have decreased in developed nations where ARV is administered, but still poses a major problem in developing countries where HIV-1 incidence is high and ARV is still not yet widely available. Even in ARV treated individuals there is a concern that the prolonged survival of many HIV-1 carriers is likely to eventually result in an increased number of malignancies diagnosed. Malignancies that were found to have high incidence in HIV-infected individuals are Kaposi's sarcoma (KS), Hodgkin's disease (HD) and non-Hodgkin's lymphoma (NHL). The incidence of NHL has increased nearly 200 fold in HIV-positive patients, and accounts for a greater percentage of AIDS defining illness in the US and Europe since the advent of HAART therapy. These AIDS related lymphomas are distinct from their counterparts seen in HIV-1 seronegative patients. For example nearly half of all cases of ARL are associated with the presence of a gamma herpesvirus, Epstein Barr virus (EBV) or human herpesvirus-8 (HHV-8)/ Kaposi's sarcoma associated herpesvirus (KSHV). The pathogenesis of ARLs is complex. B-cell proliferation driven by chronic antigenemia resulting in the induction of polyclonal and ultimately monoclonal lymphoproliferation may occur in the setting of severe immunosuppression.
\end{abstract}

Keywords: Kaposi's sarcoma, lymphomas, Epstein-Barr virus, KS-associated herpesvirus, human herpesvirus 8.

\section{INTRODUCTION}

It has been over twenty years since the onset of the AIDS epidemic, and in spite of the tremendous progress made towards the understanding of the disease, the virus that causes the disease and the development of highly effective anti-retroviral treatments, the number of people infected by HIV is still staggering. As of the end of 2004, it was estimated that there were 39.4 million people newly infected with HIV, and 3.1 million deaths globally (www. UNAIDS.org). Over $2 / 3$ of infections occur in the developing world and sub-Saharan Africa. Concurrent with immunosuppression in the infected individuals are opportunistic infections and AIDS-associated diseases, including malignancies, which have increased substantially during the AIDS disease course [1,2]. Malignancies that were found to have high incidence of HIV-infected individuals

*Correspondence: Charles WOOD

Tel: 402-472-4550 Fax: 402-472-8722

E-mail: cwood1@unl.edu are Kaposi's sarcoma (KS), Hodgkin's disease (HD), nonHodgkin's lymphoma (NHL), squamous cell carcinomas, plasmacytomas, and leiomyosarcoma in children. These tumors arose due to the lack of appropriate immune response or the reactivation of etiological agents associate with these tumors in immunosuppressed HIV infected individuals. Serveral AIDS-associated malignancies were found to be associated with the viral infections. Among them, Epstein-Barr virus (EBV) was found to associate with NHL, HD, and leiomyosarcoma; Kaposi's sarcoma associated herpesvirus (KSHV) or human herpesvirus-8 (HHV-8) was found to associate with KS and primary effusion lymphoma (PEL), and human papilloma virus (HPV) was found to associate with squamous cell neoplasia. The most common malignancies seen in HIV-infected individuals are KS and HNL, and both have been classified as AIDSdefining illnesses.

\section{AIDS RELATED LYMPHOMAS}

The infectious and malignant complications of HIV have 
decreased in developed nations where potent antiretrovirals (ARV) are widely available. However, the prolonged survival of many HIV carriers is likely to eventually result in an increased number of malignancies diagnosed in these individuals. Chronically immunocompromised patients have a markedly increased risk of developing lymphoproliferative disease. The incidence of non-Hodgkin's lymphomas (NHL) is increased nearly 200 fold in HIV-positive patients and accounts for a greater percentage of AIDS defining illness in the US since the advent of HAART therapy $[3,4]$. AIDS related lymphomas (ARLs) are distinct from their counterparts seen in HIV seronegative patients. For example nearly half of all cases of ARL are associated with the presence of a gamma herpesvirus, EBV or HHV-8 [5]. ARLs are often diagnosed at a very advanced stage and frequently involve uncommon sites (oral cavity, GI tract, central nervous system) $[5,6]$. The pathogenesis of ARLs is complex. B-cell proliferation driven by chronic antigenemia results in the induction of polyclonal, and ultimately monoclonal lymphoproliferation. In addition dysregulation of cytokine pathways (interleukin- 6 and interleukin-10), coupled with bcl-6, p53, and c-myc mutations have been implicated in the pathogenesis of ARL [7].

\section{SUBTYPES OF AIDS NHLS}

AIDS NHLs may be broadly categorized into several subtypes. Large cell immunoblastic lymphoma (IBL) and diffuse large cell lymphoma (DLCL) generally occur in the setting of moderate to severe immunosuppression (CD4+ lymphocyte counts below $100 \mathrm{~mm}^{3} / \mathrm{ml}$ ). IBLs and to a lesser degree DLCLs are often associated with EBV. These tumors express the EBV encoded oncoprotein latent membrane protein-1 (LMP-1) [5-7]. LMP-1 may function in a similar manner to tumor necrosis factor receptors by activating cellular anti-apoptotic factors such as Nuclear Factor Kappa B [6, 7]. DLCLs are frequently found to contain genetic alterations in Bcl-6 [8] although the consequences of these mutations have not been fully defined.

AIDS related Burkitt's lymphoma (BL) generally occurs in more immunocompetent patients [9]. AIDS BLs share features with endemic African BL in that both overexpress c-myc due to reciprocal translocations that bring the transactivator under the influence of potent promoter sequences within the immunoglobulin (Ig) genes loci. Inactivating mutations and deletions of $\mathrm{p} 53$ are also common as in all types of BL [10]. A distinguishing feature between AIDS related and endemic BL is that the former is associated with EBV far less frequently than the latter $[9,10]$. These tumors are incredibly aggressive with brief doubling times. Flow cytometric analysis typically reveals that over $90 \%$ are in S phase. Ongoing tumor lysis syndrome even in the absence of concomitant chemotherapy is often noted. AIDS related BLs appear to carry a poor prognosis even when compared to AIDS related DLCL [11].

A recently described variant of ARL, plasmablastic lymphoma, occurs in a small percent of HIV+ patients. These tumors are generally associated with EBV and HHV8 (10). Response to conventional chemotherapy is poor and some investigators have suggested that viral targeted approaches may be beneficial [12].

A rapidly fatal subtype of AIDS NHL is Primary Central Nervous System Lymphoma (PCNSL). These tumors are most frequently classified as IBLs and occur in the most immunosuppressed patients. In contrast to PCNSL in HIV negative patients they are virtually always associated with EBV [13]. Detection of EBV sequences in the CSF by polymerase chain reaction (PCR) coupled with positive Thallium spectroscopy has proven to be a helpful diagnostic tool [14]. These patients are often afflicted by many complications of HIV infection. Standard therapy with conventional chemotherapy combined with radiation therapy results in only about a 4 month survival although long term remission has been reported in patients treated with high dose Zidovudine and Ganciclovir [15, 16].

The most commonly identified virus associated with AIDS related lymphomas is EBV and there is a large body of published work on the oncogenic mechanisms of this agent $[17,18]$. B-lymphocytes transformed by EBV (lymphoblastoid cell lines) in vitro express an array of virus-encoded proteins including six EBV nuclear antigens (EBNAs) and three LMPs. EBNAs are generated from differential splicing of a transcript that arises from one of two promoters (Cp or Wp) [18]. This form of latency is termed Latency III. This form of latency is common in immunoblastic lymphomas [17]. A Type II form of latency where EBNA 1, LMP-1 and LMP-2a are expressed has been identified in some EBV associated lymphomas. In Latency I (typical of Burkitt lymphomas) only EBNA-1 (generated from the Qp promoter) and EBERs are expressed $[17,18]$. Recent studies have indicated that some heterogeneity in EBV gene expression and EBNA promoter usage exists among endemic BL [19].

\section{THERAPY OF AIDS NHL}

Treatment of the AIDS NHL remains disappointing. Polychemotherapy regimens have produced similar results although regimens that combine potent antiretrovirals with conventional chemotherapy may prove superior [20]. HIV positive patients often have poor bone marrow reserve which compromises the ability to deliver full dose chemotherapy. Concomitant opportunistic infections may also lead to a 
decrease in chemotherapy delivery. In general, response and survival rates for common NHL regimens are lower than for an HIV negative population. Complete responses occur but tend to be of shorter duration with frequent relapses. Our experience has been that patients concomitantly diagnosed with HIV infection and lymphomas do better with antiretroviral and anti-lymphoma therapy than do those who develop lymphoma after becoming refractory to antiretrovirals. A recently completed study performed by the NCI sponsored AIDS malignancy consortium (AMC) demonstrated the feasibility of concomitant chemotherapy with HAART [21]. Probably the best reported results for chemotherapy in AIDS NHL were from Dr. Little's group at the National Cancer Institute. Using the EPOCH regimen, the group achieved remission in 22 of 24 patients with a progression free survival of 23 months. These patients had favorable prognostic factors (median CD4+ lymphocyte count of $233 \mathrm{~mm}^{3} / \mathrm{ml}$ ) [20]. Enhanced toxicity of rituximab and CHOP chemotherapy was recently noted in a large multi-center trial conducted by the AMC [22]. The addition of rituximab to standard-dose $\mathrm{CHOP}$ as compared to CHOP alone led to increased infectious complications and deaths attributable to sepsis. It is possible that delayed recovery of humoral immunity could contribute to this increased risk of life-threatening bacterial infections in HIV-infected patients. There have been several reports on the feasibility and efficacy of high dose chemotherapy and autologous stem cell transplant for ARL $[23,24]$. It is reasonable to assume that patients with well controlled HIV and good performance status should be considered candidates for this therapy. Newer approaches that may benefit patients with ARL include EBV specific cytotoxic $\mathrm{T}$ cells and agents that activate the lytic program of gamma herpesviruses thereby sensitizing the tumors to antivirals $[25,26]$.

\section{KAPOSI's SARCOMA}

Kaposi's sarcoma was first described by Moritz Kaposi in 1872 in several cases of multi-focal pigmented sarcoma in elderly Mediterranean men. There are four forms of KS. The first is known as the classic KS or sporadic KS. They are mainly found in the elderly male population in Mediterranean countries, such as Italy [28]. The lesions tend to be found in the lower extremities and are generally non-aggressive. The second type is known as the endemicAfrican KS; it is more aggressive than the classic KS and can also involve the lymph nodes. This form of KS was seen in the African continent prior to the HIV epidemic and was found in adults (both male and female) and in children [29]. The third is the iatrogenic form of KS, which normally occurs after transplantation in patients treated with immunosuppressive medication. This form of KS seems to vary in geographical prevalence, and is more common in individuals of Mediterranean descent [30]. The fourth form of KS is the AIDS-KS. This is a very aggressive type of KS, first described in early 1980's in homosexual men [31]. AIDS-KS not only involves skin, but also the lymph nodes and often disseminates to lungs, gastrointestinal track, liver, and spleen.

$\mathrm{KS}$ is composed of a mixture of irregular shaped, round capillaries, and slit-like endothelium-lined vascular spaces and spindle-shape cells with infiltrating mononuclear cells. It is not clear whether KS represents a clonal neoplastic process or a polyclonal inflammatory lesion. Studies have shown that varying monclonality, oligoclonality, and polyclonality from lesions of various patients [32]. The origin of the KS spindle cells is also not clear; it has been suggested that KS cells represent a heterogeneous population of cells, arising from a pluripotent mesenchmal precursor cells, and may be of lymphatic endothelial cell origin [33].

\section{HUMAN HERPESVIRUS AND KS}

An infectious agent has long been suspected in the development of KS; herpesvirus-like particles were found in short-term KS tissue culture, and were subsequently identified as cytomegalovirus [34], but the involvement of CMV in KS has not been confirmed. In 1994, a novel human herpesvirus was identified by Chang and Moore [35] using representational difference analyses. This virus is now known as KSHV or HHV-8, it is found to be necessary but not sufficient for the development of all types of KS. It is clear that other co-factors, such as immunosuppression, are required for $\mathrm{KS}$ development. $\mathrm{KSHV}$ is found in all $\mathrm{KS}$ lesions, and is mainly located in the vascular endothelial cells and perivascular spindle-shaped cells [36]. KSHV infection is not commonly found in low-risk population but found commonly in individuals at risk for KS.

KSHV belongs to the $\gamma$-herpesvirus family, which can further be divided into two subgroups, $\gamma-1$ or lymphocrytovirus and $\gamma-2$ or rhadinovirus. EBV is the prototype of $\gamma-1$ virus and the simian herpesvirus saimini is the prototype of $\gamma-2$ herpesvirus [37]. KSHV is classified as a $\gamma-2$ rhadinovirus and is the first human virus of this subfamily identified. Like other herpesviruses, HHV-8 is a double-stranded deoxyribonucleic acid (DNA) virus. Its genome is linear, is about $165 \mathrm{kbp}$ in length, and contains at least 87 viral genes. A feature of some DNA viruses, particularly of herpesviruses and KSHV, is the ability of these viruses to incorporate or pirate host genes into their genome: these genes can then play a role in the replication, survival, and transformation functions of the virus. KSHV was found to encode human homologue genes that regulate cell cycling like cyclin $\mathrm{D}$, growth factors like 
interleukin 6, or genes that may prevent programmed cell death such as bcl-2. Deciphering the functions of these viral genes will lead to a better understanding of viral pathogenesis and oncogenesis.

Unlike most other herpesviruses, KSHV infection does not seem to be widely distributed in most populations. The detection of KSHV infection relies on the presence of antibodies against either lytic and/or latent antigens and varies among the different tests that were used in different seroprevalence studies. In general, the frequency of infection appears to be low in North America, certain Asian countries, and in Northern European nations such as the United Kingdom and Germany, with most studies reporting a seroprevalence rate in normal blood donors of less than 5\% [2, 38-40]. In these countries the seroprevalence of KSHV in different risk groups mirrors the incidence of AIDS KS, with a seroprevalence rate of between $25-50 \%$ among homosexual men. In other countries such as Italy, Greece, and Israel, especially Southern Italy, the infection rate seems to be much higher in the general population, and is more variable, ranging between 5-35\%. In contrast to North America and Europe, KSHV infection is widespread in the African continent. High seroprevalence rates between 40 to $50 \%$ have been found in Central, West, as well as South Africa [41-44]. Therefore, KSHV seroprevalence tracks very closely with KS, with the highest infection rate in geographic areas where classic or endemic forms of KS are more common. KS has a particularly high incidence in Central African countries like the Republic of Congo, Uganda, and Zambia; these countries also have the highest KSHV infection rates in the world [42]. Very little is known about KSHV infection in China even though EBV infection was found to be ubiquitous. There were only two reported studies in China; the study by Dilnur et al [45] found that KSHV was associated with KS in China. The study by Du et al [46] in the outskirt of China in the Xinjiang autonomy region, where there is a high incidence of HIV-1 infection, showed that there was a high HHV-8 infection rate. The study found KSHV infection varied among individuals of different racial origin, it was highest in the Khalkhas population at about $48 \%$ and lowest in the Kazak and Han population at over 12\%, but the specimens were screened without dilution and the reproducibility of the assay was not determined, and the prevalence among different risk groups was not studied. Thus, there is a need to perform a systematic comparison of risk groups using established assays.

\section{PRIMARY EFFUSION LYMPHOMAS}

In addition to KS, KSHV has also been associated with several other AIDS-associated neoplasms, primary effusion lymphomas, and multi-centric Castleman's disease.
Primary effusion lymphoma (PEL) was first identified as a subset of body-cavity-based lymphomas, which subsequently was called PELs [47]. PELs are unique as they were found to contain KSHV DNA are most frequently found in men and in AIDS patient. This type of lymphoma is distinguished from others as having a distinctive morphology, bridging large cell immunoblastic lymphoma and anaplastic large cell lymphoma. PELs often present as lymphomatous effusions in the pleural, peritoneal, and /or pericardial cavity. These cells usually CD20 negative but often express CD45 marker but lack B-cell-associated antigens. PELs are B cell origin with clonal immunoglobulin gene rearrangements. Most PELs are co-infected with EBV and lack e-myc gene rearrangements. PELs are extremely rare tumors, and estimated to be about $0.13 \%$ of all AIDS-related malignancies in AIDS patients in the US [48]. Thus, KSHV-associated lymphomas represent a rare, distinct pathobiologic category which often, but not always, associates with an effusion in AIDS patients. The role of KSHV in the development of these lymphomas is not clear since this type of malignancies is still rare even in the populations with high KSHV seroprevalence rate. However, KSHV has always been found in these lymphomas, suggesting that this virus is necessary, but other factors must be needed for the development of PELs. These factors could be EBV infection and/or immunosuppression. Recently solid tumor variants with plasmablastic features have been reported and these tumors tend to be rapidly fatal although recent data suggests that some PEL lines are quite sensitive to inhibition of NF- $\kappa \mathrm{B}$ [49].

\section{MULTI-CENTRIC CASTLEMAN'S DISEASE}

Multi-centric Castleman's disease (MCD) has also been associated with KSHV infection. MCD is a rare and poorly understood B cell lymphoproliferative disorder with vascular proliferation in the germinal centers, and is though to be related to immune dysregulation [50]. KSHV is found in almost all cases of MCD in AIDS patients and in about $50 \%$ of cases of MCD in HIV negative individuals, suggesting that there is an association between KSHV and MCD at least in HIV-positive cases [51]. However, the role of KSHV in the pathobiology of MCD is not well understood, and it is not clear whether there are any clinical differences between those with and without KSHV.

\section{IMPACT OF HAART ON KS}

Since the beginning of the AIDS epidemic in the early 1980's, AIDS-KS has become one of the most common AIDS-associated malignancies with HIV-infected homosexual males at the highest risk, and those with AIDS had a $50 \%$ lifetime rate of developing KS early in the HIV epidemic [52]. However, the rate of AIDS-KS has since 
steadily declined both in the US and Europe [53]. It has been suggested that the disease may have shifted from an early disease to a late manifestation during the HIV disease course. Since the introduction of highly active antiretroviral therapy, a further major decrease in AIDS-KS was further observed [54], and therapy has now made AIDS-KS a relatively rare tumor in treated HIV-infected individuals [55]. Several studies have shown that there was a marked decrease in KS incidence since HAART was introduced, a decline of as high as 80-fold was observed. In addition regression of KS following treatment has been reported [4, 56-59]. Interestingly, the reduced KS risk was only observed with HAART, but not with double or single antiHIV drugs [60]. Even though the incidence of KS in the treated HIV-infected individuals in the western world has decreased dramatically, in the setting where HAART is still not widely available, such as sub-Saharan Africa, AIDS-KS still remains a major problem.

\section{ACKNOWLEDGEMENTS}

This work was supported in part by PHS grants HD39620, CA76958, and NCRR COBRE grant RR15635 to Charles WOOD,

\section{REFFERENCES}

1 Lim ST, Levine AM. Recent advances in acquired immunodeficiency syndrome (AIDS)-related lymphoma. CA Cancer J Clin 2005; 55:229-41;260-1;264.

2 Scadden DT. AIDS-related malignancies. Annu Rev Med 2003; 54:285-303.

3 Cote TR, Biggar RJ, Rosenberg PS, et al. Non-Hodgkin's lymphoma among people with AIDS: incidence, presentation and public health burden. AIDS/Cancer Study Group. Int J Cancer 1997; 73:645-50.

4 Rabkin CS, Testa MA, Huang J, Von Roenn JH. Kaposi's sarcoma and non-Hodgkin's lymphoma incidence trends in AIDS Clinical Trial Group study participants. J AIDS 1999; 21 Suppl 1:S31-3.

5 Carbone A. AIDS-related non-Hodgkin's lymphomas: from pathology and molecular pathogenesis to treatment. Hum Pathol 2002; 33:392-404.

6 Ambinder RF. Epstein-Barr virus associated lymphoproliferations in the AIDS setting. Eur J Cancer 2001; 37:1209-16.

7 Boshoff C, Weiss R. AIDS-related malignancies. Nat Rev Cancer 2002; 2:373-82.

8 Nador RG, Chadburn A, Gundappa G, et al. Human immunodeficiency virus (HIV)-associated polymorphic lymphoproliferative disorders. Am J Surg Pathol 2003; 27:293-302.

9 Levine AM. Challenges in the management of Burkitt's lymphoma. Clin Lymphoma 2002; 3 Suppl 1:S19-25.

10 Carbone A. Emerging pathways in the development of AIDSrelated lymphomas. Lancet Oncol 2003; 4:22-9.

11 Lim ST, Karim R, Nathwani BN, et al. AIDS-related Burkitt's lymphoma versus diffuse large-cell lymphoma in the pre-highly active antiretroviral therapy (HAART) and HAART eras: significant differences in survival with standard chemotherapy. $\mathrm{J}$ Clin Oncol 2005; 23:4430-8.

12 Cioc AM, Allen C, Kalmar JR, et al. Oral plasmablastic lymphomas in AIDS patients are associated with human herpesvirus 8 . Am J Surg Pathol 2004; 28:41-6.

13 Newell ME, Hoy JF, Cooper SG, et al. Human immunodeficiency virus-related primary central nervous system lymphoma: factors influencing survival in 111 patients. Cancer 2004; 100: 2627-36.

14 Cingolani A, De LA, Larocca LM, et al. Minimally invasive diagnosis of acquired immunodeficiency syndrome-related primary central nervous system lymphoma. J Natl Cancer Inst 1998; 90:364-9.

15 Raez L, Cabral L, Cai JP, et al. Treatment of AIDS-related primary central nervous system lymphoma with zidovudine, ganciclovir, and interleukin 2. AIDS Res Hum Retroviruses 1999; 15:713-9.

16 Roychowdhury S, Peng R, Baiocchi RA, et al. Experimental treatment of Epstein-Barr virus-associated primary central nervous system lymphoma. Cancer Res 2003; 63:965-71.

17 Carter KL, Cahir-McFarland E, Kieff E. Epstein-barr virus-induced changes in B-lymphocyte gene expression. J Virol 2002; 76:10427-36.

18 Young LS, Rickinson AB. Epstein-Barr virus: 40 years on. Nat Rev Cancer 2004; 4:757-68.

19 Kelly GL, Milner AE, Tierney RJ, et al. Epstein-Barr virus nuclear antigen 2 (EBNA2) gene deletion is consistently linked with EBNA3A, -3B, and -3C expression in Burkitt's lymphoma cells and with increased resistance to apoptosis. J Virol 2005; 79: 10709-17.

20 Yarchoan R, Tosato G, Little RF. Therapy insight: AIDS-related malignancies - the influence of antiviral therapy on pathogenesis and management. Nat Clin Pract Oncol 2005; 2:406-15.

21 Ratner L, Lee J, Tang S, et al. Chemotherapy for human immunodeficiency virus-associated non-Hodgkin's lymphoma in combination with highly active antiretroviral therapy. J Clin Oncol 2001; 19:2171-8.

22 Kaplan LD, Lee JY, Ambinder RF, et al. Rituximab does not improve clinical outcome in a randomized phase 3 trial of CHOP with or without rituximab in patients with HIV-associated nonHodgkin lymphoma: AIDS-Malignancies Consortium Trial 010. Blood 2005; 106:1538-43.

23 Krishnan A, Molina A, Zaia J, et al. Durable remissions with autologous stem cell transplantation for high-risk HIV-associated lymphomas. Blood 2005; 105:874-8.

24 Re A, Cattaneo C, Michieli M, et al. High-dose therapy and autologous peripheral-blood stem-cell transplantation as salvage treatment for HIV-associated lymphoma in patients receiving highly active antiretroviral therapy. J Clin Oncol 2003; 21:44237.

25 Kurokawa M, Ghosh SK, Ramos JC, et al. Azidothymidine inhibits NF-kappaB and induces Epstein-Barr virus gene expression in Burkitt lymphoma. Blood 2005; 106:235-40.

26 Rooney CM, Roskrow MA, Smith CA, Brenner MK, Heslop HE. Immunotherapy for Epstein-Barr virus-associated cancers. J Natl Cancer Inst Monogr 1998; 23:89-93.

27 Kaposi M. Idiopathisches multiples pigmentsarkon der Haut. Arch. Dermatol Syphilis 1872; 4:265-73. 
28 Iscovich J, Boffetta P, Franceschi S, Azizi E, Sarid R. Classic kaposi sarcoma: epidemiology and risk factors. Cancer 2000; 88 : 500-17.

29 Wabinga HR, Parkin DM, Wabwire-Mangen F, Mugerwa JW. Cancer in Kampala, Uganda, in 1989-91: changes in incidence in the era of AIDS. Int J Cancer 1993; 54:26-36.

30 Franceschi S, Geddes M. Epidemiology of classic Kaposi's sarcoma, with special reference to mediterranean population. Tumori 1995; 81:308-14.

31 Friedman-Kien AE. Disseminated Kaposi's sarcoma syndrome in young homosexual men. J Am Acad Dermatol 1981; 5:468-71.

32 Gill PS, Tsai YC, Rao AP, et al. Evidence for multiclonality in multicentric Kaposi's sarcoma. Proc Natl Acad Sci U S A 1998; 95:8257-61.

33 Dupin N, Fisher C, Kellam P, et al. Distribution of human herpesvirus-8 latently infected cells in Kaposi's sarcoma, multicentric Castleman's disease, and primary effusion lymphoma. Proc Natl Acad Sci U S A 1999; 96:4546-51.

34 Giraldo G, Beth E, Huang ES. Kaposi's sarcoma and its relationship to cytomegalovirus (CMNV). III. CMV DNA and CMV early antigens in Kaposi's sarcoma. Int J Cancer 1980; 26:23-9.

35 Chang Y, Cesarman E, Pessin MS, et al. Identification of herpesvirus-like DNA sequences in AIDS-associated Kaposi's sarcoma. Science 1994; 266:1865-9.

36 Li JJ, Huang YQ, Cockerell CJ, Friedman-Kien AE. Localization of human herpes-like virus type 8 in vascular endothelial cells and perivascular spindle-shaped cells of Kaposi's sarcoma lesions by in situ hybridization. Am J Pathol 1996; 148:1741-8.

37 Roizman B, Desrosiers RC, Fleckenstein B, et al. The family Herpesviridae: An update. Arch Virol 1992; 123:425-49.

38 Edelman DC. Human herpesvirus 8-a novel human pathogen. Virol J 2005; 2:78.

39 Pellett PE, Wright DJ, Engels EA, et al. Multicenter comparison of serologic assays and estimation of human herpesvirus 8 seroprevalence among US blood donors. Transfusion 2003; 43: 1260-8.

40 Schulz TF. KSHV (HHV8) infection. J Infect 2000; 41:125-9.

41 Ariyoshi K, Schim van der Loeff M, Cook P, et al. Kaposi's sarcoma in the Gambia, West Africa is less frequent in human immunodeficiency virus type 2 than in human immunodeficiency virus type 1 infection despite a high prevalence of human herpesvirus 8. J Hum Virol 1998; 1:193-9.

42 Gao SJ, Kingsley L, Li M, et al. KSHV antibodies among Americans, Italians and Ugandans with and without Kaposi's sarcoma. Nat Med 1996; 2:925-8.

43 He J, Bhat G, Kankasa C, et al. Seroprevalence of human herpesvirus 8 among Zambian women of childbearing age without Kaposi's sarcoma (KS) and mother-child pairs with KS. J Infect Dis 1998; 178:1787-90.

44 Olsen SJ, Chang Y, Moore PS, Biggar RJ, Melbye M. Increasing Kaposi's sarcoma-associated herpesvirus seroprevalence with age in a highly Kaposi's sarcoma endemic region, Zambia in 1985. AIDS 1998; 12:1921-5.
45 Dilnur P, Katano H, Wang ZH, et al. Classic type of Kaposi's sarcoma and human herpesvirus 8 infection in Xinjiang, China. Pathol Int 2001; 51:845-52.

$46 \mathrm{Du} \mathrm{W}$, Chen G, Sun H. [Antibody to human herpesvirus type-8 in the general populations of Xinjiang Autonomous Region (A. R.)]. Zhonghua Shi Yan He Lin Chuang Bing Du Xue Za Zhi 2000; 14:44-6.

47 Cesarman E, Chang Y, Moore PS, Said JW, Knowles DM. Kaposi's sarcoma-associated herpesvirus-like DNA sequences in AIDS-related body-cavity-based lymphomas. N Engl J Med 1995; 332:1186-91.

48 Mbulaiteye SM, Biggar RJ, Goedert JJ, Engels EA. Pleural and peritoneal lymphoma among people with AIDS in the United States. J Acquir Immune Defic Syndr 2002; 29:418-21.

49 Keller SA, Schattner EJ, Cesarman E. Inhibition of NF-kappaB induces apoptosis of KSHV-infected primary effusion lymphoma cells. Blood 2000; 96:2537-42.

50 Corbellino M, Poirel L, Aubin JT, et al. The role of human herpesvirus 8 and Epstein-Barr virus in the pathogenesis of giant lymph node hyperplasia (Castleman's disease). Clin Infect Dis 1996; 22:1120-1.

51 Soulier J, Grollet L, Oksenhendler E, et al. Kaposi's sarcomaassociated herpesvirus-like DNA sequences in multicentric Castleman's disease. Blood 1995; 86:1276-80.

52 Katz MH, Hessol NA, Buchbinder SP, et al. Temporal trends of opportunistic infections and malignancies in homosexual men with AIDS. J Infect Dis 1994; 170:198-202.

53 Beral V. Epidemiology of Kaposi's sarcoma. Cancer Surv 1991; 10:5-22.

54 Lebbe C, Blum L, Pellet C, et al. Clinical and biological impact of antiretroviral therapy with protease inhibitors on HIV-related Kaposi's sarcoma. AIDS 1998; 12:F45-9.

55 Biggar RJ. AIDS-related cancers in the era of highly active antiretroviral therapy. Oncology (Williston Park) 2001; 15:43948; discussion 448-9.

56 Grulich AE, Li Y, McDonald AM, et al. Decreasing rates of Kaposi's sarcoma and non-Hodgkin's lymphoma in the era of potent combination anti-retroviral therapy. AIDS 2001; 15:629-33.

57 Jacobson LP, Yamashita TE, Detels R, et al. Impact of potent antiretroviral therapy on the incidence of Kaposi's sarcoma and non-Hodgkin's lymphomas among HIV-1-infected individuals. Multicenter AIDS Cohort Study. J Acquir Immune Defic Syndr 1999; 21 Suppl 1:S34-41.

58 Rabkin CS. AIDS and cancer in the era of highly active antiretroviral therapy (HAART). Eur J Cancer 2001; 37:1316-9.

59 Tam HK, Zhang ZF, Jacobson LP, et al. Effect of highly active antiretroviral therapy on survival among HIV-infected men with Kaposi sarcoma or non-Hodgkin lymphoma. Int J Cancer 2002; 98:916-22.

60 Jones JL, Hanson DL, Dworkin MS, Jaffe HW. Incidence and trends in Kaposi's sarcoma in the era of effective antiretroviral therapy. J Acquir Immune Defic Syndr 2000; 24:270-4. 